\title{
Cyclic tetramers from 3,5-disubstituted 4-hydroxybenzenesulfonyl chlorides. A conformational study
}

\author{
Giorgio Cevasco, Fernando Sancassan, and Sergio Thea
}

\author{
Dipartimento di Chimica e Chimica Industriale dell'Università di Genova and Consiglio \\ Nazionale delle Ricerche, Via Dodecaneso 31, 16146 Genova (Italia) \\ E-mail: seth@chimica.unige.it
}

\begin{abstract}
Dedicated to Professor Domenico Spinelli on his $70^{\text {th }}$ birthday
(received 18 Oct 02; accepted 04 Dec 02; published on the web 12 Dec 02)
\end{abstract}

\begin{abstract}
Temperature-dependent ${ }^{1} \mathrm{H}$ - NMR experiments on the cyclic tetramers $\mathbf{1 a}, \mathbf{1 b}$, and $\mathbf{1 c}$, obtained through reaction of the appropriate 3,5-disubstituted 4-hydroxybenzenesulfonyl chlorides and aliphatic tertiary amines in aprotic solvents, indicate that these cyclic compounds retain conformational flexibility. Free energies for the intra-annular rotation of the substituted benzene rings have been determined from the rate constants at the coalescence temperature. The influence of the nature of the ring substituents on the conformational barrier has been evaluated.
\end{abstract}

Keywords: $p$-Cyclophanes, cyclic tetra-arenesulfonates, dynamic ${ }^{1} \mathrm{H}-\mathrm{NMR}$ spectroscopy, conformational interconversion

\section{Introduction}

Our long-term interest in sulfonyl- group transfer reactions has led us to investigate these processes from both the synthetic and the mechanistic standpoints. ${ }^{1}$ In particular, we have found that the reactions of several aliphatic amines (and pyridine) with both 3,5-dimethyl- and 3,5dichloro-4-hydroxy-benzenesulfonyl chloride in aprotic solvents afforded products, henceforth identified as $\mathbf{1 a}$ and $\mathbf{1 b}$ respectively, in quite satisfactory yields. ${ }^{2} \mathrm{H}$ - NMR spectroscopy, and elemental- and MS analyses suggested that both $\mathbf{1 a}$ and $\mathbf{1 b}$ had cyclic tetrameric structures. Subsequently, X-ray crystallographic analysis of compound $\mathbf{1 b}$ provided conclusive evidence of its nature as a cyclic tetrasulfonate ester. ${ }^{3}$ In the crystal, the four phenolic oxygen atoms lie in a roughly planar square conformation; the benzene rings are alternatively above and below the plane of the four oxygens, from which they are tilted by $c a . \pm 30^{\circ}$. As a result, the size of the cavity internal to the macrocycle is strongly reduced in this conformation, which is 'frozen' in 
the solid state. Nevertheless, inspection of space-filling molecular models suggests that in solution these molecules should attain conformational flexibility.

Therefore, owing to the potential interest of this class of cyclophanes in the field of hostguest chemistry, it seemed to us worthwhile to assess the role played by substituents on the macrocycle's conformational mobility, which should depend reasonably on factors such as the number and position of the substituents in the benzene rings as well as their steric and electronic features.

Here we report our first results from temperature-dependent ${ }^{1} \mathrm{H}$ - NMR experiments carried out at $200 \mathrm{MHz}$ in 1,1,2,2-tetrachloroethane- $\mathrm{d}_{2}$ solution on the aforementioned compounds 1a and $\mathbf{1 b}$ as well as on the novel octamethylcarboxylate $\mathbf{1 c}$, which allowed us to assess the coalescence temperatures and hence to calculate the free energies for the intra-annular rotation of the substituted benzene rings.

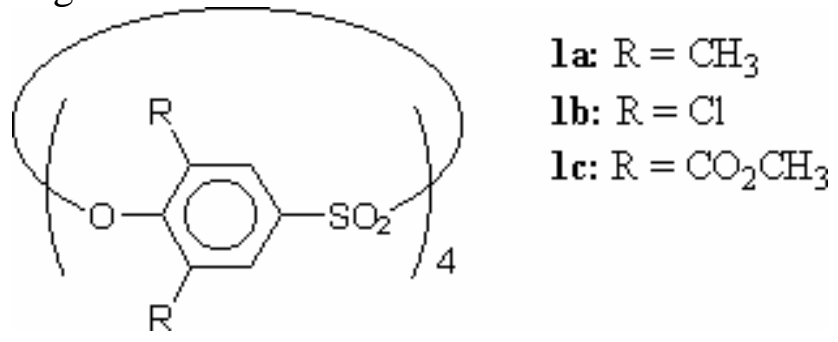

\section{Results and Discussion}

The interconversion among conformers of substrates 1a-c has been studied by temperaturedependent ${ }^{1} \mathrm{H}$ - NMR measurements at $200 \mathrm{MHz}$ in 1,1,2,2-tetrachloroethane- $d_{2}$ (TCE- $d_{2}$ ). In these studies, the resonance signals of greatest utility are those arising from aromatic protons. Tetramer 1a exhibits two moderately broad singlets at room temperature, $1 \mathrm{ppm}$ apart from each other, which broaden further as the temperature increases, until they coalesce into a single signal at $69{ }^{\circ} \mathrm{C}$. The coalescence point is reached when the width at half-maximum of the single signal corresponds to the value of the difference $\left(v_{\mathrm{a}}-v_{\mathrm{b}}\right)$ between the frequencies of the two separated signals. ${ }^{4}$ Substrate $\mathbf{1 b}$ displays two doublets at room temperature, $0.79 \mathrm{ppm}$ apart from each other, exhibiting increasing broadening as the temperature increases, until they coalesce at $101{ }^{\circ} \mathrm{C}$. Also, the ester derivative 1c exhibits two doublets at room temperature, separated from each other by $0.61 \mathrm{ppm}$, showing some broadening as the temperature increases, but at $110{ }^{\circ} \mathrm{C}$ they are still separated. An analogous study in DMSO- $d_{6}$ was possible only for $\mathbf{1 a}$, as the other tetramers undergo decomposition on heating. Indeed, the aromatic protons of 1a in DMSO- $d_{6}$ exhibit two moderately broadened singlets at room temperature which coalesce at $65{ }^{\circ} \mathrm{C}$. In any experiment, after the coalescence point was reached, further increase in temperature caused a sharpening of the signal, while cooling down to room temperature again produced a ${ }^{1} \mathrm{H}$ - NMR spectrum superimposable on the starting one.

On the basis of these data it could be inferred that the studied tetramers prefer to attain a conformation similar to that found for $\mathbf{1 a}$ in the solid state, where the two protons of each 
aromatic ring are not equivalent. When conformational interconversion is very slow on the NMR time scale, two doublets are detected. This is the case for $\mathbf{1 b}$ and $\mathbf{1 c}$ at room temperature (it is conceivable that this could happen also for 1a below room temperature). As the temperature increases, the interconversion rate increases and the two signals broaden accordingly. Coalescence is approached when the interconversion frequency approaches the frequency difference $\left(v_{\mathrm{a}}-v_{\mathrm{b}}\right)$ observed between the two separate signals during a slow exchange process.

The present study employs conventional methods ${ }^{5}$ to analyze the temperature-dependent ${ }^{1} \mathrm{H}$ NMR data and to determine barriers to the conformational change for each tetramer. Assuming that a first-order kinetic law is followed and provided that the transmission coefficient is one, the rate constant at the coalescence temperature can be calculated from the equation

$$
\mathrm{k}_{\text {coal }}=\pi\left[\left(v_{\mathrm{a}}-v_{\mathrm{b}}\right)^{2}+6 \mathrm{~J}_{\mathrm{ab}}{ }^{2}\right]^{1 / 2} / 2^{1 / 2}
$$

where $v_{a}-v_{b}$ is the chemical shift difference (in hertz) between the two separate signals and $J_{a b}$ is the observed coupling constant, if any. For the presently studied compounds, however, the contribution of the coupling constant term is negligible.

In turn, the activation energy at the coalescence temperature is given by the following equation: ${ }^{6}$

$$
\Delta \mathrm{G}_{\text {coal }}^{\neq}=\mathrm{RT} \ln \left(6.62 \times 10^{12} / \mathrm{k}_{\text {coal }}\right)
$$

The results are shown in the Table and are in the range usually found in related systems. ${ }^{5,6,7}$ It is interesting to note that the rates of the conformational change do not seem to depend simply on the steric hindrance of substituents, as expressed by their van der Waals radii (chlorine $1.8 \AA$, methyl group $2.0 \AA$ ). ${ }^{8}$ Indeed, it is well known that the spatial requirement of a substituent arises from the balance of several effects, which can be different under different conditions. ${ }^{9}$ In the present system, most likely owing to superimposition of electrostatic effects onto plain steric ones, the conformational interconversion is slower for the chloro- than for the methylsubstituted tetramer.

Table 1. ${ }^{1} \mathrm{H}$ - NMR data of aromatic protons, coalescence temperature, and free energy of activation at the coalescence temperature for the conformational change in tetramers $\mathbf{1} \mathbf{a}-\mathbf{c}$ at 200 $\mathrm{MHz}$

\begin{tabular}{ccccccc}
\hline & Substituent & Solvent & $v_{\mathrm{a}}-v_{\mathrm{b}}(\mathrm{Hz})$ & $\mathrm{J}_{\mathrm{ab}}(\mathrm{Hz})$ & $\mathrm{t}_{\text {coal }}\left({ }^{\circ} \mathrm{C}\right)$ & $\Delta \mathrm{G}_{\text {coal }}^{\neq}(\mathrm{kcal} / \mathrm{mol})^{\mathrm{a}}$ \\
\hline 1a & Me & TCE- $d_{2}$ & 203 & - & 69 & 15.9 \\
& & DMSO- $d_{6}$ & 215 & - & 65 & 15.7 \\
1b & Cl & TCE- $d_{2}$ & 165 & 2.2 & 101 & 17.6 \\
1c & COOMe & TCE- $d_{2}$ & 127 & 2.4 & $>110$ & $>18.2$ \\
\hline
\end{tabular}

${ }^{\mathrm{a}}$ Uncertainties of $\Delta \mathrm{G}^{\neq}$values: $\pm 0.1 \mathrm{kcal} / \mathrm{mol}$. 
A tentative explanation could be that during conformational interconversion each chlorine atom (bearing a negative fractional charge, presumably) must get into close proximity to the other benzene rings as well as to their $\mathrm{Cl}$ substituents. This could well account for the moderate free energy difference observed (ca. $1.7 \mathrm{Kcal} / \mathrm{mole}$ ). A similar outcome has been reported previously for a related system. ${ }^{9}$

One might speculate whether the chlorine derivative $\mathbf{1 b}$ is likely to be solvated by TCE- $d_{2}$ more efficiently than the methyl derivative 1a, as this could contribute to slowing down its conformational change. This could be a matter for further investigations; however such interaction is not expected to be important. Although the effect of changing the solvent from TCE- $d_{2}$ to DMSO- $d_{6}$ could be tested only for the methyl derivative 1a, it did not appear to have a meaningful effect on the interconversion rate of this compound.

Studies on further tetramers from 3-monosubstituted- and 3,5-disubstituted-4hydroxybenzenesulfonyl chlorides are in progress.

\section{Experimental Section}

General Procedures. ${ }^{1} \mathrm{H}$ - and ${ }^{13} \mathrm{C}$ - NMR spectra were recorded on a Varian Gemini 200 spectrometer at 200 and $50 \mathrm{MHz}$ respectively. After adjustment of the spectral parameters and zero-filling to $64 \mathrm{~K}$, a digital resolution of $0.00016 \mathrm{ppm}(0.031 \mathrm{~Hz})$ for ${ }^{1} \mathrm{H}$ and $0.0031 \mathrm{ppm}$ for ${ }^{13} \mathrm{C}$ was achieved. Tetramethylsilane was used as internal standard. The experiments at variable temperature were carried out employing either 1,1,2,2-tetrachloroethane- $\mathrm{d}_{2}$ or DMSO- $\mathrm{d}_{6}$ (Aldrich). In each experiment, after a coarse scanning of temperature in steps of $10{ }^{\circ} \mathrm{C}$, a fine scanning was performed in a range close to the coalescence temperature.

Tetramers $\mathbf{1 a}$ and $\mathbf{1} \mathbf{b}$ were prepared as previously reported. ${ }^{2}$

Synthesis of tetramer 1c. From 2-hydroxy-iso-phthalic acid, obtained by oxidation of 2hydroxy-3-methylbenzoic acid, ${ }^{10}$ the corresponding dimethyl ester was easily prepared as described. ${ }^{11}$ The ester, recrystallized from ethanol, was treated with chlorosulfonic acid and, after the usual workup, the required dimethyl 5-chlorosulfonyl-2-hydroxy-iso-phthalate, having m.p. $115-6{ }^{\circ} \mathrm{C}$, was obtained in good yield. ${ }^{1} \mathrm{H}-\mathrm{NMR}\left(\mathrm{CDCl}_{3}\right): \delta 12.57(\mathrm{~s}, 1 \mathrm{H}), 8.70(\mathrm{~s}, 2 \mathrm{H}), 4.03(\mathrm{~s}$, $6 \mathrm{H})$.

To a cooled solution $\left(0{ }^{\circ} \mathrm{C}\right)$ of the sulfonyl chloride $(1.4 \mathrm{~g}, 4.5 \mathrm{mmol})$ in anhydrous acetonitrile $(45 \mathrm{ml})$ a solution of triethylamine $(0.5 \mathrm{~g}, 5 \mathrm{mmol})$ in anhydrous acetonitrile $(10 \mathrm{ml})$ was added dropwise with stirring. The solution was stirred at room temperature overnight. After completion of the reaction, as judged by TLC, the solvent was removed under reduced pressure and the resulting solid was repeatedly rinsed with water and dried. After column chromatography on silica gel, (methylene chloride / diethyl ether 10:1 as eluent) the product was finally recrystallized from dioxane-diethyl ether affording $0.9 \mathrm{~g}$ (73\% yield) of 1c which had m.p. higher than $300{ }^{\circ} \mathrm{C} .{ }^{1} \mathrm{H}-\mathrm{NMR}\left(\mathrm{CDCl}_{3}\right): \delta 8.75(\mathrm{~d}, \mathrm{~J}=2.5 \mathrm{~Hz}, 4 \mathrm{H}), 8.14(\mathrm{~d}, \mathrm{~J}=2.5 \mathrm{~Hz}, 4 \mathrm{H}), 4.09$ 
(s, 12H), $3.71(\mathrm{~s}, 12 \mathrm{H}) .{ }^{13} \mathrm{C}-\mathrm{NMR}\left(\mathrm{CDCl}_{3}\right) \quad 163.76$ and 162.93 (COO), 149.40, 135.58, 135.13, 133.53, 129.92 and 128.62 (aromatic carbons), 53.61 and $53.49\left(\mathrm{CH}_{3}\right)$. Anal. Calcd for $\mathrm{C}_{40} \mathrm{H}_{32} \mathrm{~S}_{4} \mathrm{O}_{28}$ : C, 44.12; H, 2.96. Found: C, 44.34; H, 2.90.

\section{References}

1. Thea, S.; Vigo, D.; Cevasco, G. J. Chem. Soc., Perkin Trans. 2 2002, 611 and references therein.

2. Cevasco, G.; Penco, S.; Thea, S.; Busetti, V. Tetrahedron 1991, 47, 7353.

3. Cevasco, G.; Penco, S.; Thea, S.; Busetti, V. J. Chem. Res. (S) 1993, 102.

4. Breitmaier, E. Structure Elucidation by NMR in Organic Chemistry, $3^{\text {rd }}$ Edn; Wiley: N. Y., 2002; p 62.

5. See for instance: Oki, M. Applications of Dynamic NMR Spectroscopy to Organic Chemistry; VCH Publishers: Deerfields Beach, FL, 1985.

6. Gutsche, C. D.; Bauer, L. J. J. Amer. Chem. Soc. 1985, 107, 6052.

7. (a) Butler, D. L.; Shang, M.; Mann, D.; Johnston, M. R. ARKIVOC, (xii) 2001, 27. (b) Lai Y.-H.; Hui-Tin Yap A.; Novak I. J. Org. Chem. 1994, 59, 3381. (c) Jorgensen, W. L.; Nguyen, T. B.; Sanford, E. M.; Chao, I.; Houk, K. N.; Diderich, F. J. Am. Chem. Soc. 1992, 114, 4003.

8. Pauling, L. The Nature of Chemical Bond; $3^{\text {rd }}$ Edn; Cornell University Press: Ithaca, N.Y., 1960.

9. Förster, H; Vögtle, F. Angew. Chem. Int. Ed. Engl. 1977, 16, 429.

10. Todd, D.; Martell, A.E. Organic Synthesis; Coll. Vol. V, p 617.

11. Whol, A. Chem. Ber. 1910, 43, 3474. 